\title{
Macrophage-derived netrin-1 contributes to endometriosis- associated pain
}

\author{
Shaojie Ding ${ }^{1}$, Xinyue Guo ${ }^{2}$, Libo Zhu ${ }^{1}$, Jianzhang Wang ${ }^{1}$, Tiantian $\mathrm{Li}^{2}$, Qin Yu ${ }^{1}$, Xinmei Zhang ${ }^{1 \wedge}$ \\ ${ }^{1}$ Department of Gynecology, Women's Hospital, Zhejiang University School of Medicine, Hangzhou, China; ${ }^{2}$ Zhejiang University School of \\ Medicine, Hangzhou, China \\ Contributions: (I) Conception and design: S Ding, X Guo, X Zhang; (II) Administrative support: X Zhang; (III) Provision of study materials or \\ patients: S Ding, L Zhu, J Wang; (IV) Collection and assembly of data: S Ding, T Li, Q Yu; (V) Data analysis and interpretation: X Guo, L Zhu, J \\ Wang; (VI) Manuscript writing: All authors; (VII) Final approval of manuscript: All authors. \\ Correspondence to: Xinmei Zhang, MD, PhD. Department of Gynecology, Women's Hospital, School of Medicine, Zhejiang University, 1 Xueshi \\ Road, Hangzhou 310006, China. Email: zhangxinm@zju.edu.cn.
}

Background: Endometriosis-associated pain can be considered a type of neuropathic pain. Netrin-1 is an axon guidance cue that regulates axonal attraction or rejection in neural injury and regeneration. However, whether netrin-1 plays a role in endometriosis-associated pain remains unclear. This study aimed to determine the role of netrin-1 in endometriosis-related pain.

Methods: Peripheral blood, peritoneal fluid, and endometrial tissues were sampled from women with $(n=37)$ and without endometriosis ( $n=23)$. Lipopolysaccharide (LPS) and interferon gamma (IFN- $\gamma$ ) were used to stimulate human monocytic cell lines (THP-1) and rat alveolar macrophage-derived cell lines (NR8383) to induce M1 phenotype macrophages. Serum netrin-1 concentrations, endometrial expression levels of netrin-1, and its receptors including deleted in colorectal cancer (DCC), A2B adenosine receptor (A2BAR), uncoordinated B receptor (UNC5B), uncoordinated C receptor (UNC5C) and Down's syndrome cell adhesion molecule (DSCAM) were assessed. The polarization phenotypes of the peritoneal macrophages were identified by detecting the marker expression of M1/M2 macrophages via flow cytometry. The expression levels of M1 markers and netrin-1 in THP-1/NR8383 cells were determined.

Results: The expression levels of netrin-1 in serum and endometriotic lesions were significantly higher in women with endometriosis, and were positively correlated with the severity of endometriosis-associated pain. Netrin-1 was co-expressed with CD68 (a macrophage marker) in endometriotic lesions and was synthesized and secreted by THP-1 and NR8383 cells in the process of M1 polarization. In women with endometriosis, peritoneal macrophages were polarized towards the M1 phenotype. In addition, increased expression of DCC and A2BAR, and decreased expression of UNC5B, UNC5C and DSCAM were found in endometriotic lesions.

Conclusions: These results suggest that netrin-1 production by macrophages in endometriotic lesions may play an important role in endometriosis-associated pain.

Keywords: Endometriosis; pain; netrin-1; macrophage; polarization

Submitted Mar 04, 2020. Accepted for publication Oct 10, 2020.

doi: 10.21037/atm-20-2161

View this article at: http://dx.doi.org/10.21037/atm-20-2161

\footnotetext{
^ ORCID: 0000-0001-6474-3477.
} 


\section{Introduction}

Endometriosis is a common gynecological disease characterized by pain and infertility, which affects women of childbearing age (1). Pain symptoms in patients with endometriosis include dysmenorrhea, dyspareunia, dysuria, defecation pain and chronic pelvic pain, all of which have a significant impact on women's quality of life (2). However, despite extensive research efforts, the exact mechanisms of endometriosis-associated pain remain unclear $(3,4)$.

In 2000, Anaf et al. were first to report S100-labeled nerves infiltrating in endometriotic lesions, with the percentage of nerves being significantly higher in the lesions of women who suffered severe endometriosis-associated pain (5). In subsequent studies, elevated specific makers for sensory, sympathetic, and parasympathetic nerves (6-8) and growth factors such as nerve growth factor (NGF), brain derived neurotrophic factor (BDNF) and neurite growth factor 2 (NEGF2) (9-13) were identified in different types of endometriotic lesions, all of which correlated with endometriosis-associated pain. Therefore, endometriosisassociated pain was considered to be a type of neuropathic pain. Moreover, in a rat model of endometriosis, autotransplanted endometriotic lesions were shown to develop autonomic and sensory innervation (14). In other studies, growth-associated protein 43 (GAP-43), a marker for neurite outgrowth and regeneration, was expressed in nerve fibers infiltrating in the endometriotic lesions of peritoneal and deep infiltrating endometriosis $(15,16)$. However, it is still unclear how the nerve fibers in endometriotic lesions sprout abnormally.

Netrins are members of the laminin superfamily which share a similar amino acid terminal sequence (17). The name netrin is derived from the Sanskrit word "netr", meaning "to guide", because of their role in axon guidance (18). Until now, three secreted netrins (netrins 1, 3 and 4), and two glycosylphosphatidylinositol-anchored membrane proteins, netrins G1 and G2, have been identified in mammals. Netrin Gs regulate axon guidance by forming synaptic interactions between neurons with the transmembrane netrin G ligands NGL1 and 2. The secreted netrins can bind to the receptors of deleted in colorectal cancer (DCC), neogenin or uncoordinated (UNC5) A-D, causing axonal attraction or rejection $(19,20)$. Recent studies have shown that netrins also participate in angiogenesis, cell proliferation, migration and tumorigenesis by binding to the receptors of DCC, neogenin, UNC5, Down's syndrome cell adhesion molecule (DSCAM), CD146 and A2B adenosine receptor (A2BAR) (21-24).

It has been demonstrated that netrin-1, the most studied guidance cue, triggers an attraction effect through DCC and neogenin, or a repulsion effect via UNC5 A-D (17). In the central nervous system, netrin 1 is secreted by ventricular zone neural progenitors and floor-plate cells in the ventral embryonic spinal cord $(25,26)$. In the process of peripheral neural injury and regeneration, increased levels of netrin-1 are mainly produced by Schwann cells (27). Netrin-1 expression has also been found to be increased in hypoxic conditions (24), and in inflammatory and other disease conditions such as obesity (28), type 2 diabetes (29), acute lung injury (30), atherosclerosis (31) and abdominal aortic aneurysm (AAA) (32). However, it is not clear whether netrin-1 is involved in the pathogenesis of endometriosis.

Co-localization of netrin-1 and CD68, a marker of macrophages, has been identified in atherosclerotic plaques (31), adipose tissues (28) and inflamed aortic vessel walls (32), suggesting that macrophages may participate in inflammation by secreting netrin-1. In fact, the inflammatory microenvironment of endometriosis can promote macrophage infiltration $(33,34)$, which plays a crucial role in the etiology and pathogenesis of this disease including inflammatory response (35), angiogenesis (34), proliferation (36) and neurogenesis (37). The interaction between macrophages and nerve fibers contributes to neuroinflammation and pain generation in endometriosis (37). A large number of up-regulated molecules released by nerve fibers in endometriotic lesions such as monocyte chemotactic protein-1 (MCP-1), colony-stimulating factor 1 (CSF-1) and leukemia inhibitory factor (LIF), are responsible for the recruitment of macrophages from vessels within the lesions $(38,39)$. Conversely, infiltrating macrophages in the lesions can in turn mediate neurogenesis by secreting neurotrophins, semaphorins, and vascular epithelial growth factor (VEGF) $(37,39,40)$. Macrophage activation is closely associated with endometriosis. However, whether macrophages differentiate into classically activated macrophages (pro-inflammatory, M1) or alternatively activated macrophages (anti-inflammatory, M2) (41) remains highly debated, as does the issue of polarization of M1/M2 macrophages in endometriosis $(33,34,42,43)$, Therefore, it is important to explore the role of macrophage-mediated netrin-1 in the pathogenesis of endometriosis.

In the present study, we aimed to investigate the role of macrophage-mediated netrin-1 in endometriosisassociated pain. Firstly, we detected expressions of netrin-1 
and its receptors in endometriotic lesions. Secondly, we localized netrin-1 and macrophages in endometriotic lesions. Thirdly, we determined polarization phenotypes of peritoneal macrophages. Lastly, we observed the expression and secretion of netrin- 1 after macrophage M1 polarization was induced in vitro.

We present the following article in accordance with the MDAR checklist (available at http://dx.doi.org/10.21037/ atm-20-2161).

\section{Methods}

\section{Patients}

A total of 60 women with endometriosis (case group, $\mathrm{n}=37$ ) and without endometriosis (e.g., other benign gynecologic diseases excluding chronic pelvic pain, control group, $n=23$ ) who were admitted to the Women's Hospital between January 2018 and June 2018 were recruited for this study. All participants underwent laparoscopic surgery to determine the presence and staging of endometriosis. The specimen was confirmed by pathologists after surgery. In the endometriosis group, 17 women were at stage III while 20 were at stage III-IV, according to the Revised American Fertility Society Scoring system. The types of pain associated with endometriosis included dysmenorrhea, dyspareunia, dysuria, defecation pain and chronic pelvic pain. The severity of pain was documented using a standardized questionnaire with a Visual Analog Scale (VAS, 0-10) as previously described (44). The pain scale was subdivided into 10 grades, graduated from "no pain" on the left side of the scale to "maximum pain imaginable" on the right side of the scale. Pain symptoms were reported in $48.6 \%(n=18)$ and $0 \%(n=0)$ of the endometriosis and nonendometriosis groups, while infertility was $24.3 \%(n=9)$ and $17.4 \%(n=4)$, respectively. None of the participants had received hormone therapy in the 6 months prior to surgery. The study was conducted in accordance with the Declaration of Helsinki (as revised in 2013). Informed consent was obtained from all participating patients. This study was approved by the Human Ethics Committee of the Women's Hospital, School of Medicine, Zhejiang University (no. 20190012).

\section{Samples collection}

Peripheral blood samples were obtained 1 day before surgery, and red fresh endometriotic lesions and endometrial tissues were collected during the surgical procedure. The blood or cell supernatants were centrifuged at $1,000 \mathrm{~g}$ for 10 minutes, and the supernatants were transferred into $1.5 \mathrm{~mL}$ tubes and stored at $-80{ }^{\circ} \mathrm{C}$ until processing. Of the 37 women with endometriosis, 16 (43.2\%) had ovarian endometriosis, 11 (29.7\%) had peritoneal endometriosis and $10(27.0 \%)$ had deeply infiltrating endometriosis. Half of the endometrial tissue was frozen in $-80{ }^{\circ} \mathrm{C}$ for mRNA detection, and the other half was immersed in formalin (Solarbio) for further immunohistochemical and immunofluorescence staining.

\section{Enzyme-linked immunosorbent assay (ELISA)}

The concentrations of netrin- 1 in serum or culture supernatants were quantified by ELISA kits (Cusabio) according to the manufacturer's instructions.

\section{Quantitative real-time polymerase chain (qRT-PCR) and Western blot analyses}

Total RNA was extracted from the endometrial samples or cells with TRIzol reagent (Takara) and reversed by a PrimeScript Reverse Transcription (RT) reagent kit (Takara) according to the manufacturer's recommendations. SYBR Premix Ex Taq kit (Takara) was used for quantitative polymerase chain reaction (PCR) and the fold change was determined through the $2^{-\Delta \Delta C t}$ method. The primers for netrin-1, receptors, and inflammatory factors were synthesized from Generay and the sequences are listed in Tables 1,2. Western blot analysis was used to test the netrin-1 protein expression levels with the netrin-1 antibody in THP-1 and NR8383 cells in the M1 polarization process. In the Western blot, the primary antibodies of netrin-1 (1:1,000, ab126729, rabbit monoclonal, Abcam), and GAPDH (1:1,000, Mab5465-100; mouse monoclonal, Multi Sciences) as well as a secondary antibody $(1: 5,000$, ab97051/ab97023; Abcam) were used and detected using an electrochemiluminescence detection kit (Biological Industries, Beit-Ha'emek).

\section{Immunobistochemical staining}

In brief, serial sections of $6 \mu \mathrm{m}$ thickness were immunostained using the corresponding antibody for 1 hour at room temperature. The specific antibodies of netrin-1 (1:50, ab122903, goat polyclonal, Abcam), DCC 
Table 1 Primer sequences of netrin-1 receptors

\begin{tabular}{lcc}
\hline Primer & Forward $\left(5^{\prime}-3^{\prime}\right)$ & Reverse $\left(5^{\prime}-3^{\prime}\right)$ \\
\hline Actin $\left(h^{*}\right)$ & AGAAGGATTCCTATGTGGGCG & GGATAGCACAGCCTGGATAGCA \\
Netrin-1 $(\mathrm{h})$ & CGACCCCAAGAAGGCGCACCCGCCC & CCTCCTGCTCGTTCTGCTTG \\
DCC $(\mathrm{h})$ & AGCAGGGAGCTCTATGTCCA & ACTGACTTCTTCCTGCTCCG \\
Neogenin $(\mathrm{h})$ & CAGCCTGTGATTAGTGCCCA & TCATAGGTGGGAGGTCCTGG \\
UNC5A $(\mathrm{h})$ & CAAGGTTGCTGAGCTGCTG & GTCCAGGTGGAGTTTCTGGG \\
UNC5B $(\mathrm{h})$ & TGTGCATGCAAATGCTGGAG & TGTCTGTGTCGAAGTCACGG \\
UNC5C $(\mathrm{h})$ & TCAATGCTCACTTCCCGGAC \\
UNC5D $(\mathrm{h})$ & ACAATTCGCTCCACACTTCCCAG \\
DSCAM $(\mathrm{h})$ & TCAATGGTGGGGCCTTTTGT & AGACGACAGTGATGTACGCC \\
CD146 $(\mathrm{h})$ & CAAGAGGTAGTGTTTCCAGC & GTTCGCTCTTACGAGACGGG \\
A2BAR $(\mathrm{h})$ & CCCTCACACCAGACTCCAAC & ATTCGTGGTTCCATCCCAGG \\
\hline
\end{tabular}

*, $\mathrm{h}=$ human.

Table 2 Primer sequences of netrin-1 and M1 phenotype markers

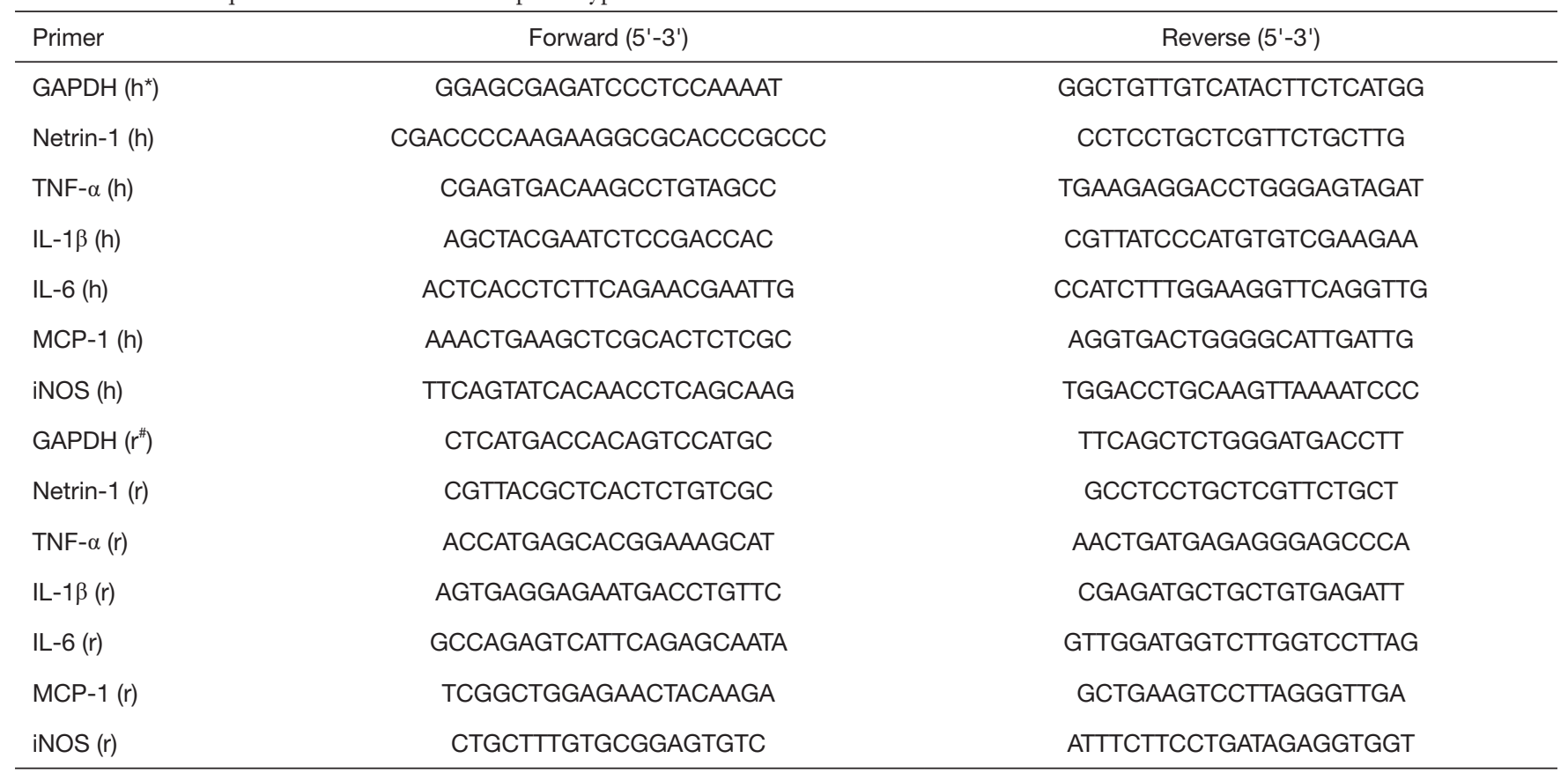

*, $\mathrm{h}=$ human; " $\mathrm{r}$ = rat. TNF, tumor necrosis factor; IL, interleukin; iNOS, nitric oxide synthase 2; LPS, lipopolysaccharide; INF, interferon; MCP-1, monocyte chemotactic protein-1.

(1:300, bs-0592R, rabbit polyclonal, Bioss), UNC5B (1:300, bs-11492R, rabbit polyclonal, Bioss) and A2BAR (1:1,000, PA5-72850, rabbit polyclonal, Invitrogen) were used to access the expression levels and localization of netrin-1 and its receptors in endometrial tissues. Envision-labeled polymer-alkaline phosphatase goat/rabbit (Dako, Glostrup) and diaminobenzidine (K5007; Dako, Glostrup) were used to visualize the antigen-antibody reaction, also known as chromogen. After washing, the sections were counterstained with Mayer's hematoxylin, dehydrated, and mounted 
with a mounting medium. The sum of the percentage $(0-3)$ and intensity scores $(0-3)$ were represented as immunohistochemistry (IHC) scores to show the expression levels of molecules. The detailed immunohistochemical process and scoring have been described previously (10). All slides were analyzed by two blinded observers.

\section{Double immunofluorescence staining}

The slides of the endometriotic lesions were incubated with the primary antibody of netrin-1 (1:500, ab126729, rabbit monoclonal, Abcam) and CD68 (1:200, ab201340, mouse monoclonal, Abcam), and then were rinsed in phosphatebuffered saline (PBS) before being mounted with the corresponding fluorescent secondary antibody (Abcam).

\section{Flow cytometric analysis}

The peritoneal macrophages were washed with an erythrocyte lysis buffer and incubated with human Fc block (1:200, BD564219, BD Biosciences) on ice. Subsequently, the cells were incubated with the $\mathrm{PE}-\mathrm{Cy}^{\mathrm{TM}} 7$-conjugated anti-CD86 (1:200, BD561128, mouse BALB/c IgG1, $\kappa$, $\mathrm{BD}$ Biosciences) and PE-conjugated anti-CD163 (1:50, BD556018, mouse BALB/c IgG1, $\kappa$, BD Biosciences) antibody for 15 minutes. For intracellular staining, the cells were fixed and permeabilized in fixation and permeabilization solution (BD54722, BD Biosciences) for 20 minutes, and incubated with the FITC-conjugated antiCD68 (1:200, BD562117, mouse BALB/c IgG2b, $\kappa$, BD Biosciences) antibody for 1 hour. The samples were then analyzed with a FACS Verse system and analyzed with the BD FACS DIVA software (BD Biosciences, United States). The PE-Cy ${ }^{\mathrm{TM}} 7$-conjugated IgG1 (1: 200, BD557872, BD Biosciences), PE-conjugated IgG1 (1:50, BD555749, BD Biosciences) and FITC-conjugated IgG2b (1:1,000, BD565379, BD Biosciences) antibodies served as control antibodies. $\mathrm{CD} 68^{+} \mathrm{CD} 86^{+} \mathrm{CD} 163^{-}$macrophages were identified as $\mathrm{M} 1$ macrophages, while the $\mathrm{CD} 68^{+} \mathrm{CD} 86^{-}$ $\mathrm{CD} 163^{+}$cells were identified as M2 macrophages.

\section{Cells intervention}

Human monocytic cell line THP-1 cells and rat alveolar macrophage-derived cell line NR8383 cells were purchased from the Stem Cell Bank at Chinese Academy of Sciences. The cells were cultured with Dulbecco's Modified Eagle
Medium/F-12 containing 15\% fetal calf sera (Gibco). The THP-1 cells were induced to the macrophages (M0) by phorbol-12-myristate-13-acetate (PMA, $20 \mathrm{ng} / \mathrm{mL}$, Sigma). Subsequently, the differentiated human THP1 macrophages and NR8383 cells were treated with lipopolysaccharide (LPS, $20 \mathrm{ng} / \mathrm{mL}$, Sigma) and interferon gamma (IFN- $\gamma, 20 \mathrm{ng} / \mathrm{mL}$, PeproTech) to further induce M1 phenotype macrophages. Next, expression levels of the M1 phenotype markers tumor necrosis factor alpha (TNF- $\alpha$ ), interleukin (IL)-1 $\beta$, IL-6, MCP-1 and nitric oxide synthase 2 (iNOS) were assessed at 1, 3, 6, 12, 24 and 48 hours after stimulation. Meanwhile, mRNA and protein expression levels of netrin-1 as well as secreted netrin-1 levels in cell supernatants were measured using qRT-PCR, Western blot and ELISA respectively.

\section{Statistical analysis}

Data were analyzed using SPSS Version 24.0 (IBM). The continuous data variables were quantified as mean \pm SEM. Differences in variables between two groups and multiple groups were analyzed using unpaired Student's $t$-test and one-way ANOVA, respectively. Nonparametric testing was used where sample sizes were insufficient to confirm normality of data distribution. Spearman's analysis was conducted to analyze the correlation between netrin-1 expression and the severity of endometriosis-associated pain. Statistical tests ( $\chi^{2}$ and Mann-Whitney $U$ test) were performed to compare the frequency and median among groups. $\mathrm{P}$ values $<0.05$ were considered statistically significant.

\section{Results}

\section{Patient characteristics}

Except for pain symptoms, there were no significant differences between the endometriosis and nonendometriosis groups with respect to their age, gravidity, parity, abortion, infertility, or cycle stage (Table 3).

\section{Netrin-1 concentrations in serum were associated with endometriosis-associated pain}

The serum concentrations of netrin-1 in women with endometriosis were significantly higher than those from women without endometriosis $(\mathrm{P}<0.05$, Figure $1 A)$, and Spearman's analysis results showed that netrin-1 
Table 3 Characteristics of patients

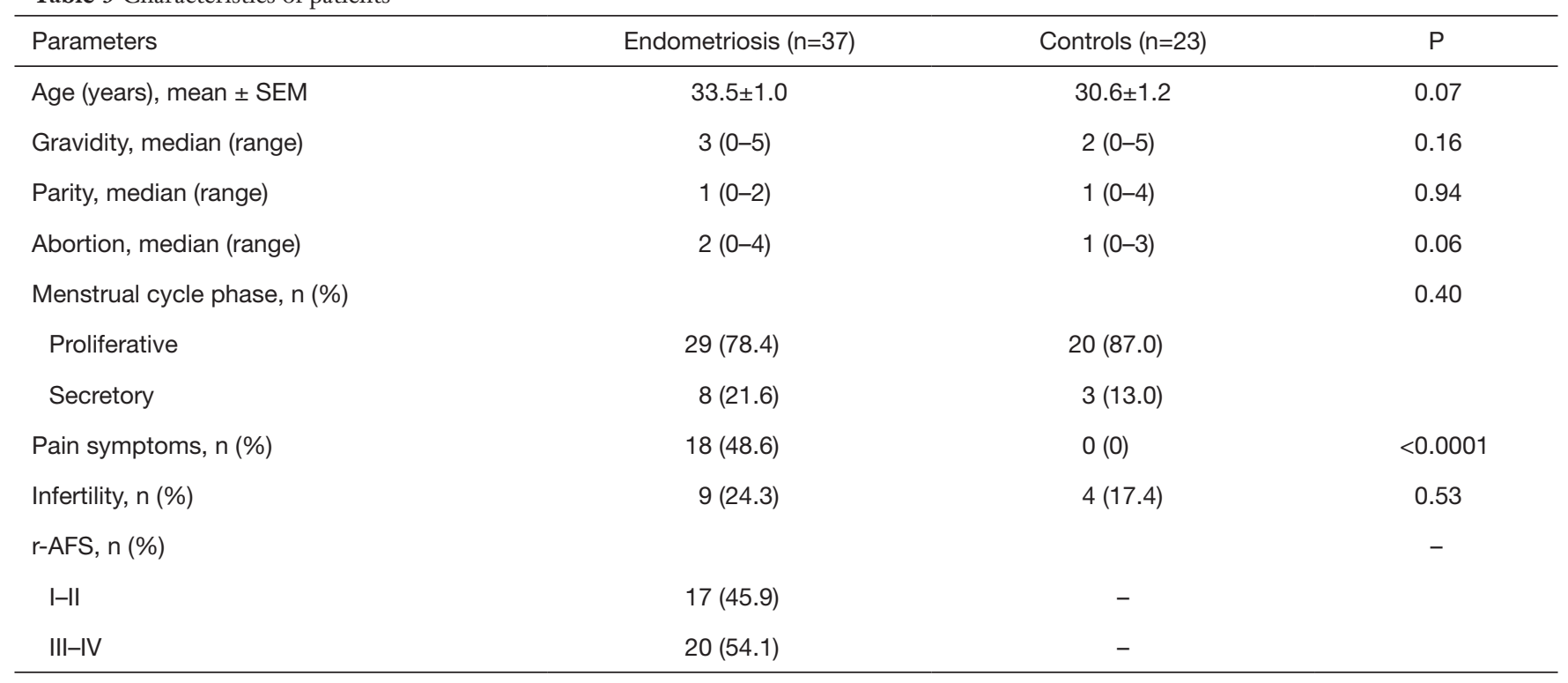

r-AFS, revised American Fertility Society; SEM, standard error of the mean.

concentrations in the serum $(\mathrm{r}=0.46, \mathrm{P}<0.01$; Figure $1 B)$ were positively correlated with the severity of endometriosisassociated pain.

\section{Netrin-1 was over-expressed in endometriotic lesions}

The mRNA expression levels of netrin-1 in endometriotic lesions were significantly higher than those in the eutopic endometrium from women with $(\mathrm{P}<0.01)$ or without endometriosis $(\mathrm{P}<0.01$, Figure $1 C)$, and were positively correlated with the severity of endometriosis-associated pain $(\mathrm{r}=0.83, \mathrm{P}<0.0001$; Figure $1 D)$. Immunohistochemical staining showed that netrin-1 was not only expressed in epithelial and interstitial vascular endothelial cells, but also expressed in endometrial stromal cells in endometriotic lesions from women with endometriosis with pain (Figure 1E) or without pain (Figure $1 F$ ), and in endothelial cells in the eutopic endometrium from women with (Figure 1G) or without (Figure $1 H)$ endometriosis. Moreover, netrin-1 was co-expressed with CD68 in endometriotic lesions (Figure 1I, $7, K, L$ ).

\section{Endometriosis polarized peritoneal macrophages towards the M1 phenotype}

$\mathrm{CD} 68^{+}$cells were recognized as peritoneal macrophages in women with endometriosis (Figure $2 A, B$ ) or without endometriosis (Figure 2C,D). Flow cytometry plots revealed that the proportion of $\mathrm{M} 1$ macrophages $\left(\mathrm{CD} 68^{+} \mathrm{CD} 163^{-}\right)$ was high in women with endometriosis, but it did not reach statistical significance (Figure $3 A$ ). Moreover, there were a significantly higher proportion of $\mathrm{CD} 86^{+} \mathrm{CD} 163^{+}$ macrophages $(\mathrm{P}<0.0001$, Figure $3 B)$, but a statistically lower proportion of $\mathrm{M} 2$ macrophages $\left(\mathrm{CD} 86^{-} \mathrm{CD}^{-} 63^{+}\right)(\mathrm{P}<0.0001$, Figure $3 C)$ and $\mathrm{CD}^{-} 6^{-} \mathrm{CD} 163^{-}$macrophages $(\mathrm{P}<0.05$, Figure $3 D)$ in women with endometriosis compared to women without endometriosis. In short, the proportion of $\mathrm{CD}^{+} 6^{+}$ macrophages significantly increased in endometriosis patients compared with those without endometriosis $(\mathrm{P}<0.0001$, Figure $3 E)$, while the proportion of $\mathrm{CD} 163^{+}$ macrophages did not differ (Figure $3 E, F$ ).

\section{Netrin-1 was secreted by macrophages}

PMA treatment induced significantly higher mRNA expression levels of IL-1 $\beta(\mathrm{P}<0.01)$, IL-6 $(\mathrm{P}<0.05)$, and iNOS $(\mathrm{P}<0.01)$; lower mRNA expression levels of TNF- $\alpha(\mathrm{P}<0.01)$; and similar mRNA levels of MCP-1 $(\mathrm{P}>0.05)$ and netrin-1 $(\mathrm{P}>0.05)$ in human THP-1 macrophages compared with untreated monocytic THP-1 cells. The mRNA expression levels of the M1 phenotype markers TNF- $\alpha$, IL-1 $\beta$, IL-6, MCP-1 and iNOS were all significantly elevated after combined stimulation of LPS and IFN $-\gamma$ within 48 hours, reaching pecks at 1 hour $(\mathrm{P}<0.05$; Figure $4 A)$, 1 hour $(\mathrm{P}<0.01$; Figure $4 B), 6$ hours $(\mathrm{P}<0.05$; Figure $4 C)$, 24 hours $(\mathrm{P}<0.01$; Figure $4 D)$ and 48 hours $(\mathrm{P}<0.05$; Figure $4 E$ ), respectively. The mRNA, protein expression 
A
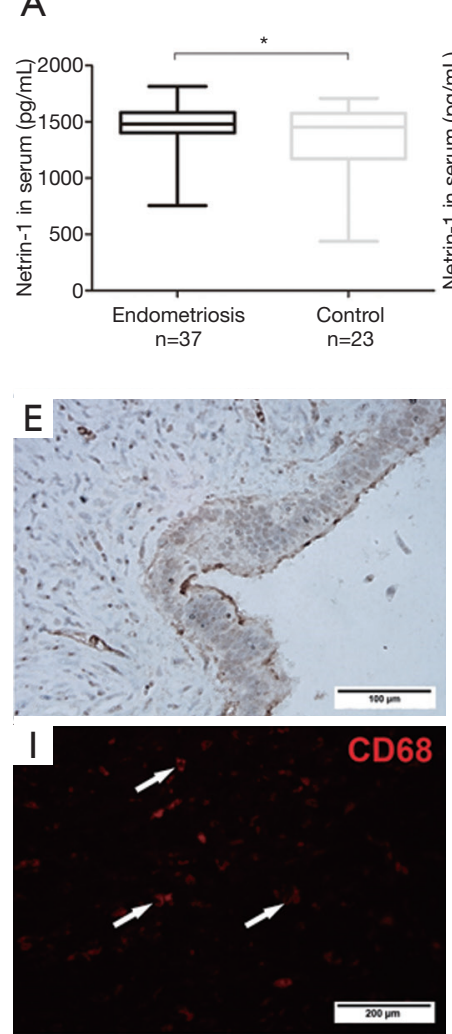

B
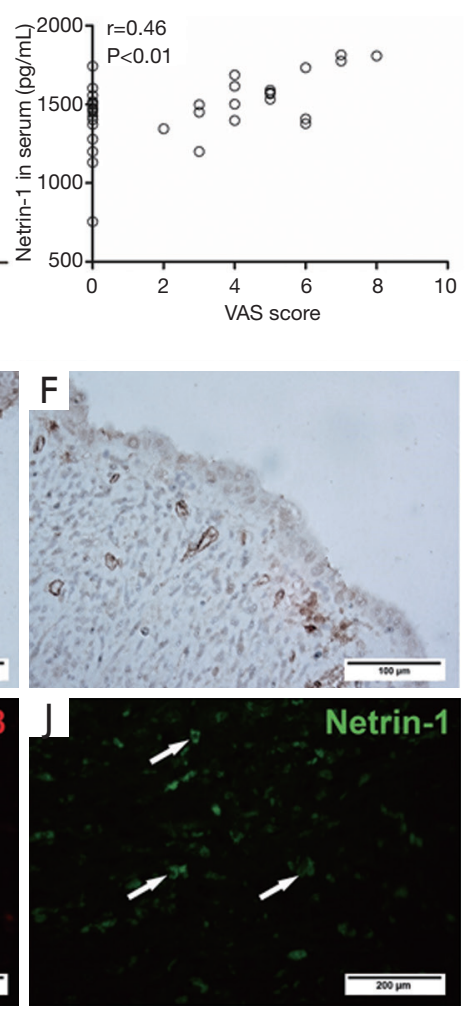

C
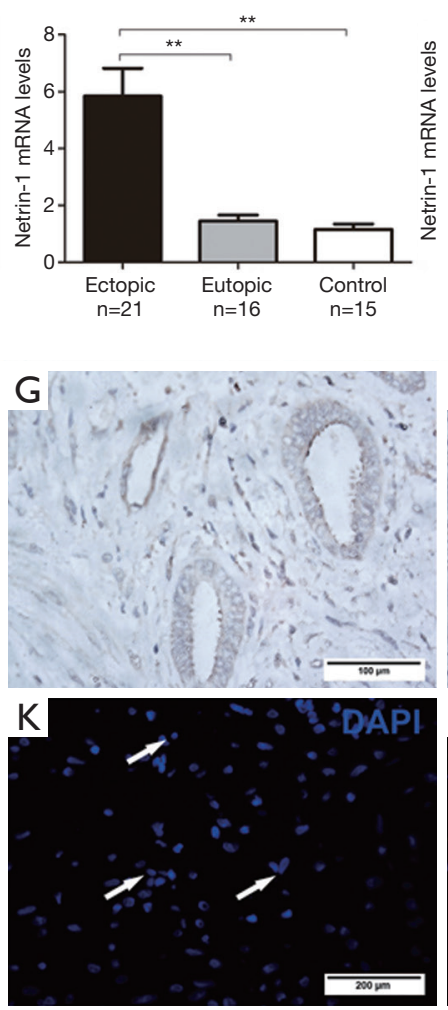

D
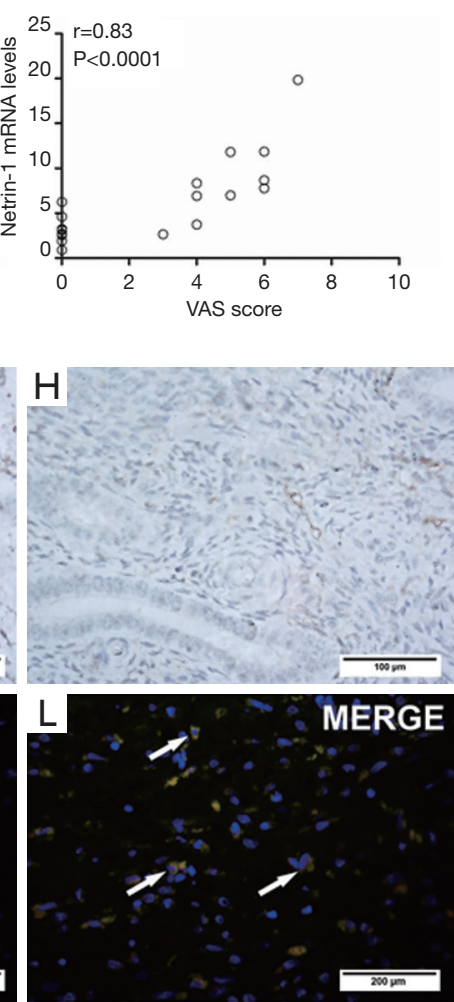

Figure 1 Netrin-1 levels in women with endometriosis. (A,B,C,D) The netrin-1 concentrations in serum (A,B) and mRNA expression levels in endometrial tissues (C,D) were tested using RT-qPCR and ELISA respectively. (E,F,G,H) The location and expression levels of netrin-1 in endometriotic lesions. (E,F) The eutopic endometria with $(\mathrm{G})$ or without $(\mathrm{H})$ endometriosis were analyzed by immunohistochemical staining. (I,J,K,L) The location of netirn-1 and CD68 in endometriotic lesions were tested by immunofluorescence double staining. Error bars show mean \pm SEM. *, $\mathrm{P}<0.05 ;{ }^{* *}, \mathrm{P}<0.01$ (one-way ANOVA and Student's $t$-test). VAS, Visual Analog Scale; SEM, standard error of the mean.

levels and supernatant concentrations of netrin-1 in PMA-differentiated human THP-1 macrophages were significantly higher at 12 hours $(\mathrm{P}<0.05$; Figure $4 F), 24$ hours $(\mathrm{P}<0.05$; Figure $4 G)$ and 48 hours $(\mathrm{P}<0.01$; Figure $4 H)$ respectively after $\mathrm{M} 1$ polarization.

In the NR8383 cell lines, the mRNA expression levels of TNF- $\alpha$, IL-1 $\beta$, IL-6, MCP-1 and iNOS all increased within 48 hours after LPS and IFN- $\gamma$ treatment, reaching pecks at 6 hours $(\mathrm{P}<0.01$; Figure 41$), 6$ hours $(\mathrm{P}<0.05$; Figure 4f), 3 hours $(\mathrm{P}<0.05$; Figure $4 K), 6$ hours $(\mathrm{P}<0.05$; Figure $4 L)$ and 12 hours $(\mathrm{P}<0.05$; Figure $4 M)$, respectively. Meanwhile, the mRNA and protein levels and supernatant concentrations of netrin-1 in the NR8383 cells were significantly elevated at 12 hours $(\mathrm{P}<0.05$; Figure $4 N), 24$ hours $(\mathrm{P}<0.05$; Figure $4 O)$ and 48 hours $(\mathrm{P}<0.0001$; Figure $4 P)$ respectively after $M 1$ polarization.

\section{Netrin-1 receptors were more expressed in endometriotic tissues}

The expression levels of different netrin-1 receptors vary greatly in different types of endometrial tissue (Figure 5). Specifically, the mRNA expression levels of DCC and A2BAR in endometriotic lesions were significantly higher than those in the eutopic endometrium from women with $(\mathrm{P}<0.01 ; \mathrm{P}<0.05)$ or without $(\mathrm{P}<0.01 ; \mathrm{P}<0.01)$ endometriosis (Figure 5 A,I). Also, neogenin mRNA expression levels were statistically higher in endometriotic lesions than those in the eutopic endometrium from women without endometriosis $(\mathrm{P}<0.01$; Figure $5 B)$. On the contrary, UNC5B, UNC5C and DSCAM mRNA expression levels in endometriotic lesions were significantly lower than those in the eutopic endometrium from women with $(\mathrm{P}<0.01 ; \mathrm{P}<0.0001 ; \mathrm{P}<0.01)$ 

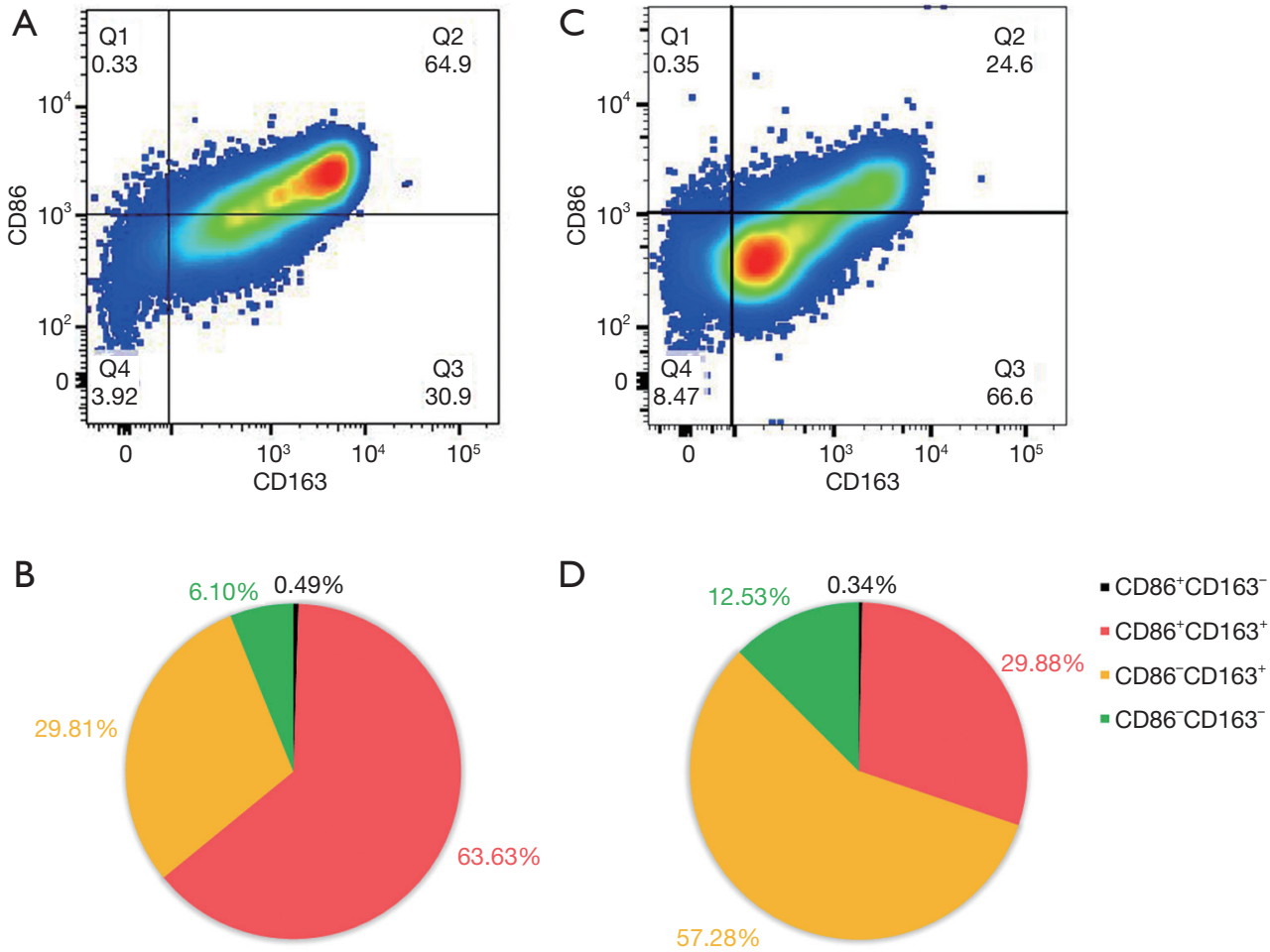

Figure 2 Polarized phenotypes of peritoneal macrophages in women with or without endometriosis. Representative dot plot and statistical chart of $\mathrm{CD}^{+} 8^{+}$cells in peritoneal fluids from endometriosis $(\mathrm{A}, \mathrm{B}, \mathrm{n}=8)$ and non-endometriosis $(\mathrm{C}, \mathrm{D}$, n=6) women by flow cytometric analysis using CD86 and CD163 markers.
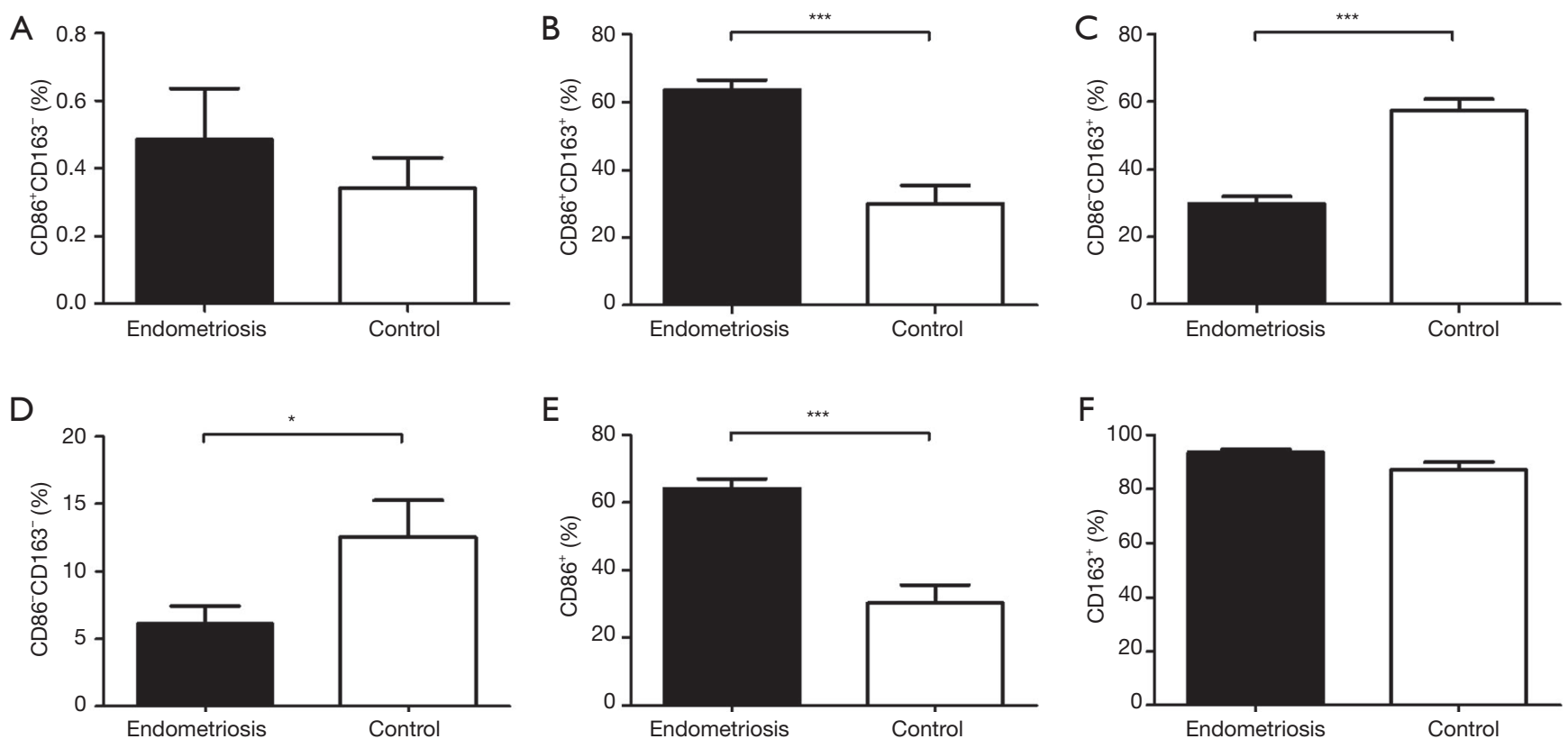

Figure 3 Different polarized phenotypes of peritoneal macrophages in endometriosis and women without endometriosis. The percentages

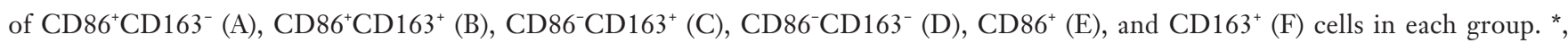
$\mathrm{P}<0.05 ;{ }^{* * *}, \mathrm{P}<0.0001$ (Student's $t$-test). 


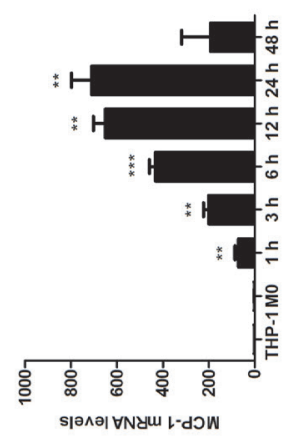

○

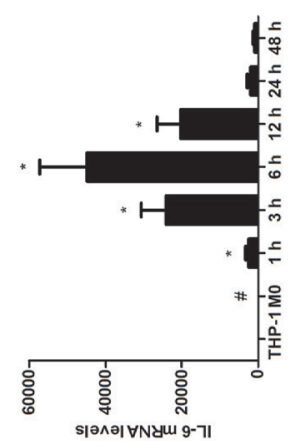

$\cup$

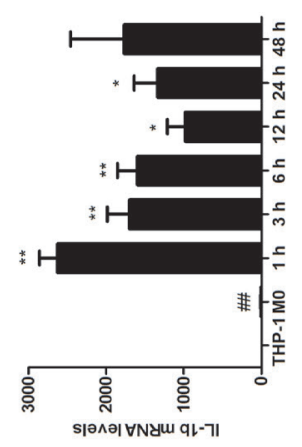

$\infty$

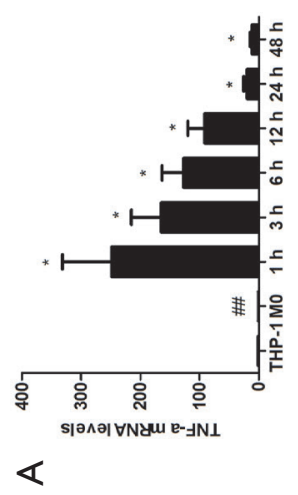

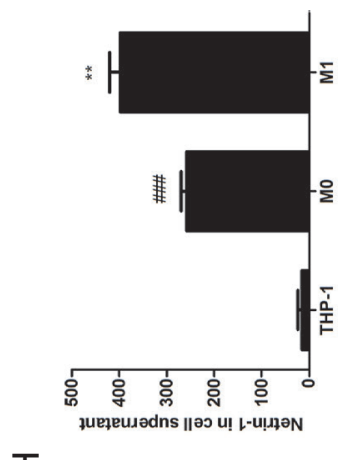

工

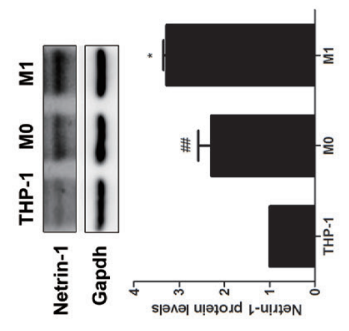

$\circlearrowleft$

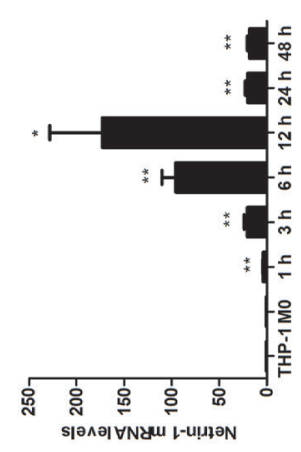

น

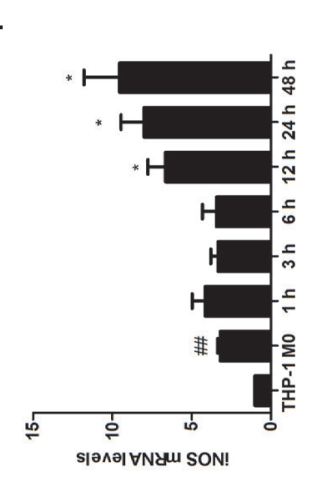

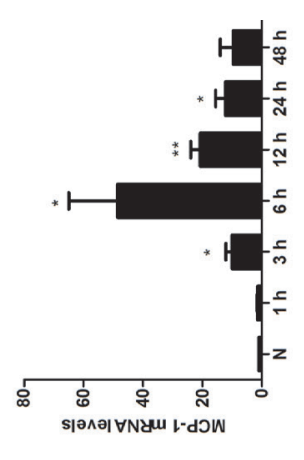

$-$

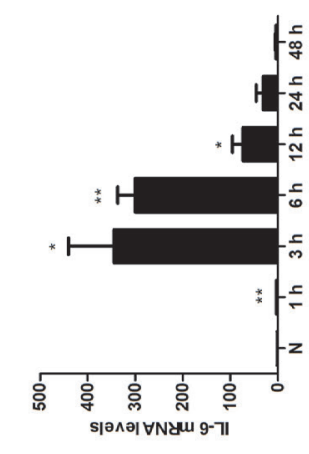

$\underline{Y}$

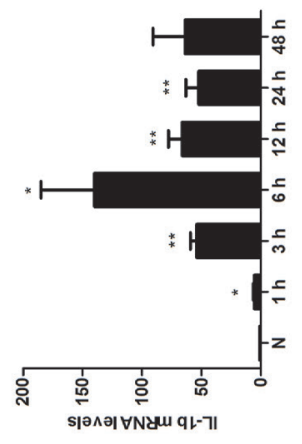

Z

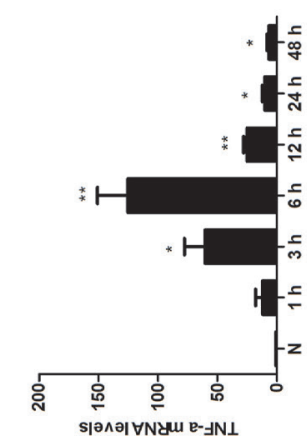

๑

O
.

i ક

Z

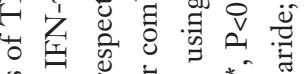

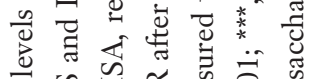

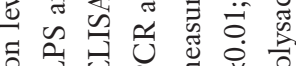

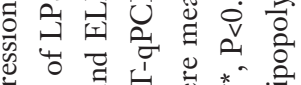

एँ

过

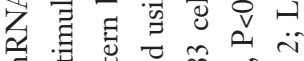

光 寻跑

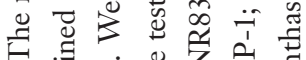

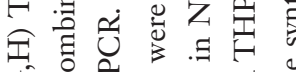

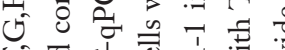

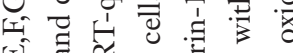

ค

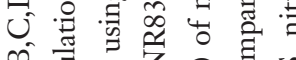
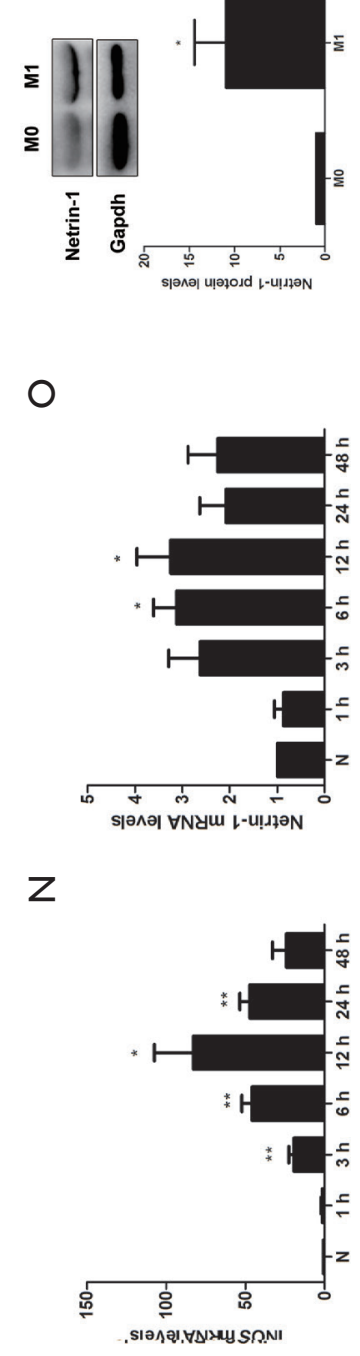

$\Sigma$

ш 

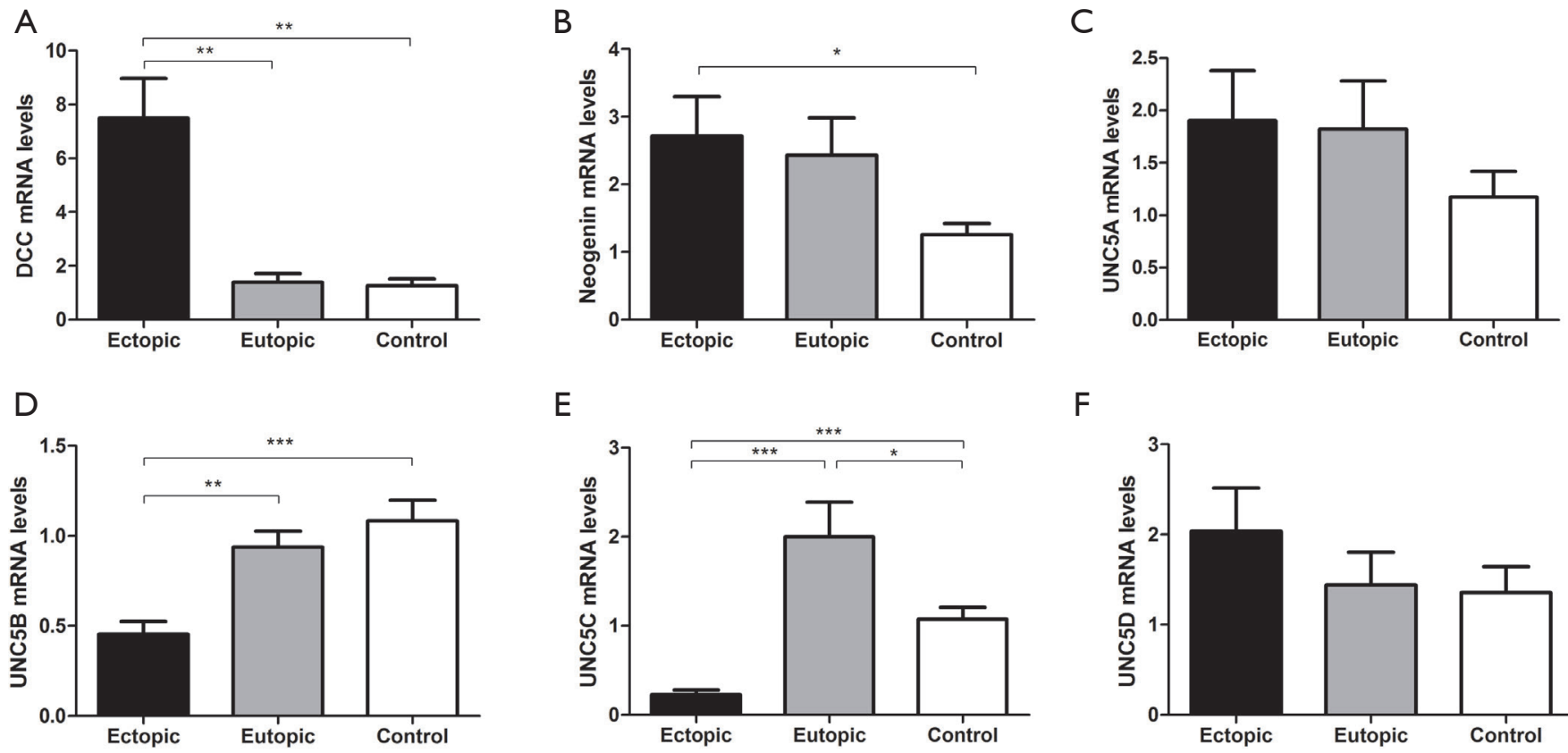

F
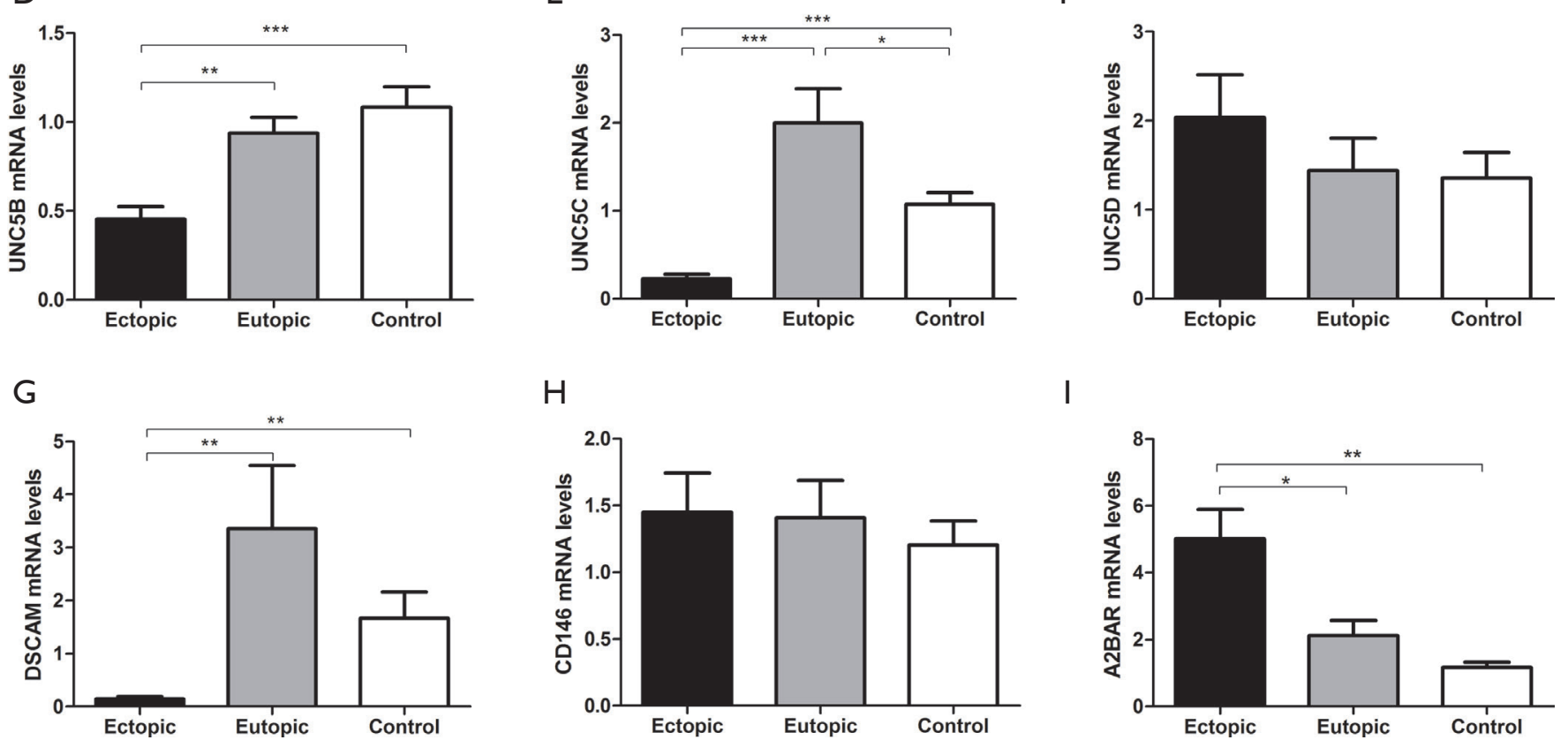

Figure 5 Expression levels of netrin-1 receptors in endometrial tissues. The mRNA expression levels of DCC (A), neogenin (B), UNC5A (C), UNC5B (D), UNC5C (E), UNC5D (F), DSCAM (G), CD146 (H) and A2BAR (I) in endometriotic lesions and eutopic endometria from women with or without endometriosis were tested using RT-qRCR. Error bars show mean $\pm \mathrm{SEM}$. * $\mathrm{P}<0.05$; ** $\mathrm{P}<0.01$; ${ }^{* * *} \mathrm{P}<0.0001$ (one-way ANOVA and Student's $t$-test). SEM, standard error of the mean.

or without $(\mathrm{P}<0.0001 ; \mathrm{P}<0.0001 ; \mathrm{P}<0.01)$ endometriosis (Figure $5 D, E, G)$. The eutopic endometrium from women with endometriosis also showed significantly higher UNC5C mRNA expression levels than those from women without endometriosis $(\mathrm{P}<0.05$; Figure $5 E)$. No statistical differences in UNC5A, UNC5B or CD146 mRNA expression levels among endometriotic lesions and the eutopic endometrium from women with or without endometriosis were found (Figure 5C,F,H).

IHC results showed that DCC was mainly expressed in the epithelial and stromal cells and the interstitium in endometriotic lesions (Figure 6A,B,C), and showed a higher IHC score in endometriotic lesions than those in the eutopic endometrium from women with or without endometriosis $(\mathrm{P}<0.0001)$. UNC5B was mainly expressed in glandular epithelial cells (Figure $6 D, E, F$ ) and was less expressed in endometriotic lesions than those in eutopic endometrium from women with $(\mathrm{P}<0.01)$ or without $(\mathrm{P}<0.05)$ endometriosis. A2BAR was widely expressed in endometriotic lesions (Figure 6G,H,I), and the IHC scores were higher than those in the eutopic endometrium from endometriosis $(\mathrm{P}<0.05)$ and non-endometriosis $(\mathrm{P}<0.05)$ women.

\section{Discussion}

This study demonstrated that netrin-1 is increased in serum 

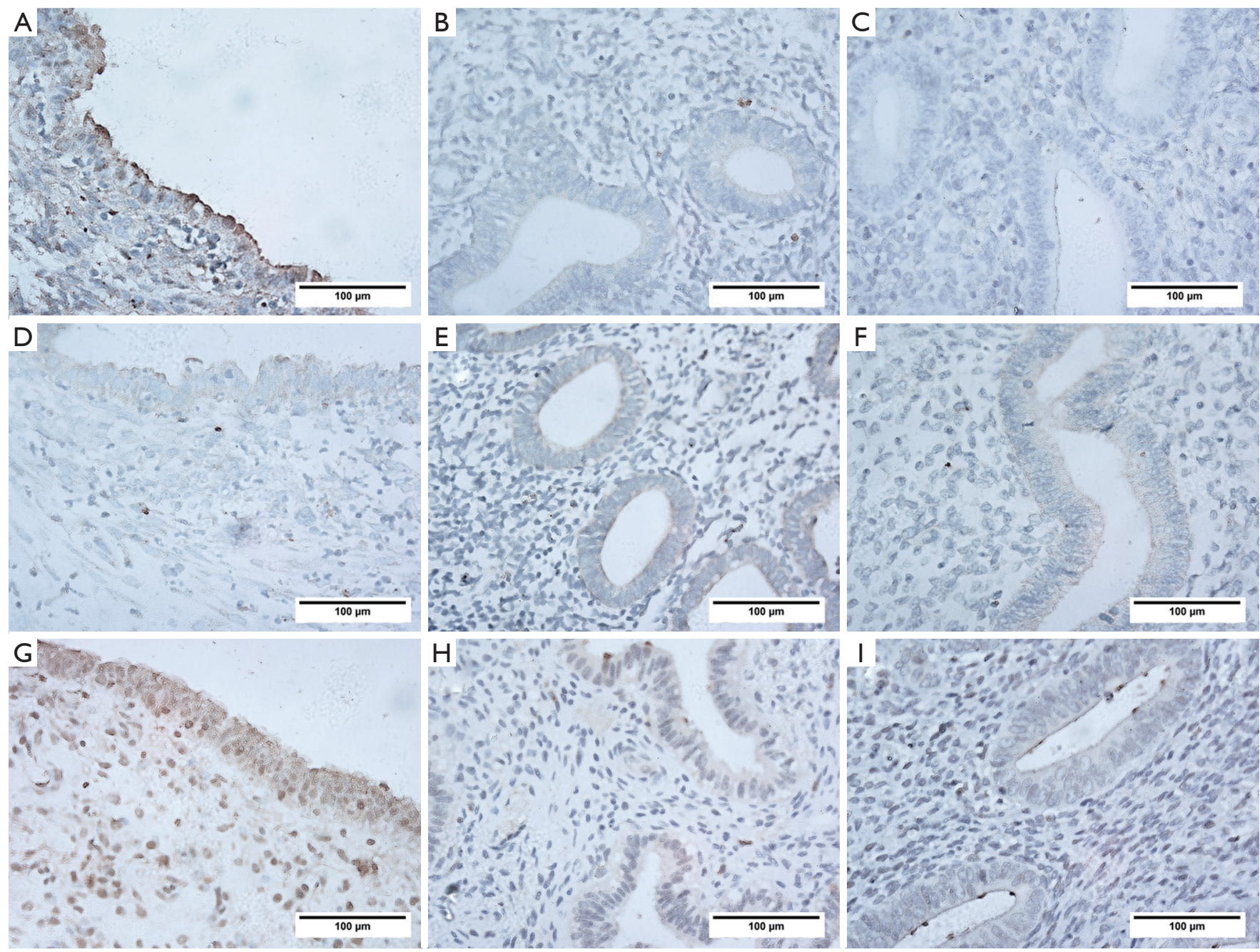

Figure 6 DCC, UNC5B and A2BAR immunoreactive staining in endometrial tissues. The locations and expression levels of DCC (A,B,C), UNC5B (D,E,F) and A2BAR (G,H,I) in endometriotic lesions (A,D,G) and eutopic endometrium from women with (B,E,H) and without $(\mathrm{C}, \mathrm{F}, \mathrm{I})$ endometriosis were measured using immunohistochemistry analysis.

and endometriotic lesions in women with endometriosis. Since netrin-1 is an axon guide molecule, we speculated that netrin-1 mediates endometriosis-associated pain by promoting nerve fiber infiltration in endometriotic lesions. In fact, netrin-1 has bi-functionality on axonal guidance. It has been reported that netrin-1 leads to axon attraction by binding to the DCC receptor or repulsion by binding to the UNC5A-D receptors in the same cells (17). Neogenin, DSCAM and CD146 also show a promoting effect on axon extension (20). The bi-functionality on axon guidance is based on the crystal structure of netrin-1 and its receptors (45). Plus, cross-links with different receptor types and the charge changes on netrin-1 and receptors also determines the promotion or inhibition of netrin-1 in axon guidance (20). Our study demonstrated that endometriotic lesions showed significantly higher expression levels of DCC and A2BAR and lower expression levels of UNC5B and UNC5C compared with the eutopic endometrium, which further supports the proposal that netrin-1 is responsible for endometriosis-associated pain by promoting nerve infiltration in endometriotic lesions. Dorsal root ganglion (DRG) neurons express DCC, neogenin and UNC5A-D receptors (46). In a rat model of sciatic nerve transection, the expression of the DCC receptor was found to be upregulated while the expression of the UNC5B and UNC5C receptors was down-regulated in sensory neurons (46). 
Transplantation of netrin-1 overexpression in bone marrow mesenchymal stem cells promotes axon regeneration and functional recovery of the sciatic nerve after crush injury (47). However, netrin-1 treatment $(500 \mathrm{ng} / \mathrm{mL})$ inhibits neurite outgrowth of adult DRG neurons in explant and dissociated cultures, which may be mediated by the UNC5A-C receptors on DRG (48). Thus, the effect of netrin-1 on nerve outgrowth is complex and the mechanism of netrin-1 involvement in endometriosis-associated pain remains to be further studied.

M1 macrophages, activated by IFN- $\gamma$, LPS or TNF- $\alpha$, participate in tissue injury, inflammatory and immune responses by producing pro-inflammatory cytokines and chemokines (49). In contrast, M2 macrophages can be activated by IL-4, IL-10, IL-13, or the transforming growth factor- $\beta$ (TGF- $\beta$ ), thus participating in tissue repair tumor angiogenesis and vessel normalization (50). Several studies have reported that the macrophages in women with endometriosis are predominantly of the M2 phenotype $\left(\mathrm{CD} 163^{+} / \mathrm{CD}^{2} 06^{+}\right)$, which play an important role in the development of endometriosis (33,43,51-53). Endometriosis is an estrogen-dependent disease, and some researchers have reported that estrogen promotes M2 polarization through the activation of the signal transducers and activators of the transcription (STAT3) and P38-mitogen-activated protein kinases (MAPK) pathway $(54,55)$. However, another study showed the opposite results with $17 \beta$-estradiol repressing the suppressor for M2 polarization by inhibiting the JAK1STAT6 signaling pathway (56). Takebayashi et al. have reported that the macrophage population slants toward M1 in the endometrium of endometriosis patients due to the significantly lower ratio of the number of CD163 or $\mathrm{CD} 206^{+}$macrophages to CD $68^{+}$macrophages (42). In this study, we found that the peritoneal macrophages of endometriosis were mainly of the $\mathrm{CD} 86^{+} \mathrm{CD} 163^{+}$ type, while those of women without endometriosis were mainly of the $\mathrm{CD} 86^{-} \mathrm{CD} 163^{+}$type (M2). The percentage of $\mathrm{CD} 86^{+}$macrophages in women with endometriosis was significantly higher than that in the control group, which displayed a unique M1/M2 polarization signature that was skewed towards the classical M1 activation phenotype. This was consistent with the subsequent results of experiments in vitro in which M1 polarization induced up-regulation of netrin-1 synthesis and secretion in human and rat cell line. A recent study also reported that netrn-1-enriched macrophages were highly expressed pro-inflammatory markers, as netrin-1 mRNA expression levels were increased in $\mathrm{CD} 68^{+} \mathrm{CD} 206^{-}$pro-inflammatory phenotypes rather than $\mathrm{CD} 68^{+} \mathrm{CD} 206^{+}$samples (32). In this study, we used $\mathrm{CD} 68^{+} \mathrm{CD} 86^{+} \mathrm{CD} 163^{-}$to label M1 and $\mathrm{CD} 68^{+} \mathrm{CD} 86^{-} \mathrm{CD} 163^{+}$to label $\mathrm{M} 2$ when analyzing the polarization phenotypes of the peritoneal macrophages, which is the most commonly used method. In the in vitro cell experiments, we used LPS and IFN- $\gamma$ to induce M1 phenotype macrophages in the THP-1/NR8383 cells, which is the most widely used method (57), and verified the macrophage polarization by detecting the expression of the inflammatory mediators. In actuality, polarization is a dynamic process as the signals are temporal and dynamic, and the use of the terms M1 and M2 is confusing due to the lack of a specific phenotypic scoring criteria $(57,58)$. Many physiological or pathological macrophages do not show a clear M1 or M2 phenotype (59), and macrophages with combinations of both M1 and M2 markers can be found during M1/M2 polarization $(60,61)$. New methods and technical advances are needed to investigate the activation and classification of macrophage.

The netrin-1 gene is a direct transcriptional target

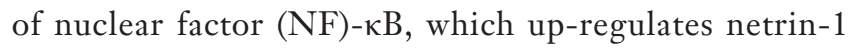
in colorectal carcinoma and mammary epithelial cells in response to inflammation (62). However, previous research has reported that activation of NF-KB represses netrin-1 expression levels in adenocarcinomic alveolar epithelial cells and dermal microvessel endothelial cells (30). In fact, macrophages from endometriosis patients show a statistically significant higher proportion of NF- $\kappa$ B nuclear translocations, and release various cytokines, growth factors and angiogenic factors to participate in endometrial fragment adhesion, proliferation and neovascularization (35). Since we only tested cell lines in vitro, primary macrophages from women with endometriosis would be more valuable in determining the amount of cytokine, time of exposure, and the competition for cytokines (58). Thus, the regulatory mechanism of netrin-1 in endometriosis macrophages needs further study.

Netrin-1 also plays a role in angiogenesis, cell migration, cell proliferation and cell survival. The present study confirmed the higher expression of netrin-1, the constant expression of CD146, and the lower expression of UNC5B in endometriotic lesions. Netrin-1-enriched macrophages also highly express pro-angiogenic markers (32), and treatment of netrin-1 with low doses $(50-200 \mathrm{ng} / \mathrm{mL})$ of endothelial cells promotes proliferation, migration and tube formation by binding to the high affinity receptor CD146 (21). However, high concentrations of netrin-1 $(1,000-2,000 \mathrm{ng} / \mathrm{mL})$ inhibit the above effects, possibly via 
the UNC5B signaling pathway (21). In endometriosis, nerve fibers are accompanied by immature blood vessels within endometriotic lesions (15). Netrin-1 also dose-dependently regulates cell migration of Schwan cell and endothelial cells by activating or inhibiting the MAPK pathway via CD146 or UNC5B receptors $(21,63,64)$. In inflammatory conditions, it has been reported that netrin-1 in endothelial cells inhibits inflammatory cell migration of leukocytes and macrophages $(32,65,66)$. This may be an anti-inflammatory response in the body, but it can lead to the accumulation of inflammatory cells in the lesions, resulting in AAA or atherosclerosis $(31,32)$. In endometriosis, macrophage retention in endometriotic lesions increases the local concentration of netrin-1, which may play a role in the infiltration of nerve fibers. In tumorigenesis, netrin-1 promotes cell survival, proliferation, invasion and migration in different types of cancer, such as prostate carcinoma, hepatocellular carcinoma, gastric cancer, and breast cancer (67-70). Although endometriosis is a benign gynecological disease, it demonstrates malignant behaviors in its adhesion, proliferation, invasion, metastasis and recurrence (71-74). Thus, elevated netrin-1 may also be involved in the growth of endometriotic lesions.

Our study has some limitations, which should be taken into account when interpreting our findings. First, in this study a total of 60 women were recruited. Different sample sizes often lead to differences in results. In order for greater validation of the present results, follow-up studies with increased sample sizes are needed to reduce experimental statistical errors. Secondly, double immunofluorescence staining showed that there were approximately $62.2 \%$ of netrin-1-expressing macrophages $\left(\mathrm{CD} 68^{+}\right.$netrin- $\left.1^{+}\right)$in the total netrin $-1^{+}$cells. Thus, another limitation in our study is that it is unclear which cells are responsible for the increased netrin-1 in endometriotic lesions. Immunohistochemical staining results showed that netrin-1 was not only expressed in epithelial and interstitial vascular endothelial cells, but also expressed in endometrial stromal cells in endometriotic lesions from women with endometriosis. In this study, we demonstrated that the expression levels of netrin-1 in serum and endometriotic lesions were significantly higher in women with endometriosis, and netrin-1 was co-expressed with CD68 in endometriotic lesions, which is consistent with previous studies in which netrin-1 was highly expressed in macrophage infiltration in atherosclerotic plaques (31), adipose tissues (28), and inflamed aortic vessel walls (32). In the in vitro studies, we found that netrin- 1 was synthesized and secreted by THP-1 and NR8383 cells in the process of M1 polarization. However, it has been reported that endothelial cells (75), as well as epithelial cells (24), can also synthesize and secrete netrin-1. Thus, further research is needed on the origin of the up-regulation of netrin-1 expression in endometriotic lesions. Last but not least, we have not studied the effects of netrin-1 on different receptors; that is, how netrin-1 causes endometriosis-associated pain. In another study, we demonstrated that netrin-1 induced angiogenesis in ovarian endometriomas through interaction with CD146 in vascular endothelial cells and promoted neurite growth and sensitization through another receptor, neogenin (76). This is an ongoing study, and we will further validate and inform our research with additional animal experiments.

In summary, the present study indicates that increased netrin-1 in women with endometriosis may play a role in endometriosis-associated pain. Targeting therapy towards netrin-1 and macrophages may not only reduce endometriosis-associated pain, but may also inhibit the progression of endometriosis.

\section{Acknowledgments}

Funding: This work was funded by National Key R\&D Program of China (grant number 2017YFC1001202) and National Natural Science Foundation of China (grant number 81974225, 81671429).

\section{Footnote}

Reporting Checklist: The authors have completed the MDAR checklist. Available at http://dx.doi.org/10.21037/atm-202161

Data Sharing Statement: Available at http://dx.doi. org/10.21037/atm-20-2161

Peer Review File: Available at http://dx.doi.org/10.21037/ atm-20-2161

Conflicts of Interest: All authors have completed the ICMJE uniform disclosure form (available at http://dx.doi. org/10.21037/atm-20-2161). XZ serves as an unpaid editorial board member of Annals of Translational Medicine from Mar 2020 to Feb 2022. The authors have no conflicts of interest to declare.

Ethical Statement: The authors are accountable for all 
aspects of the work in ensuring that questions related to the accuracy or integrity of any part of the work are appropriately investigated and resolved. The study was conducted in accordance with the Declaration of Helsinki (as revised in 2013). This study was approved by the Human Ethics Committee of the Women's Hospital, School of Medicine, Zhejiang University (grant number 20190012). Informed consent was obtained from all patients.

Open Access Statement: This is an Open Access article distributed in accordance with the Creative Commons Attribution-NonCommercial-NoDerivs 4.0 International License (CC BY-NC-ND 4.0), which permits the noncommercial replication and distribution of the article with the strict proviso that no changes or edits are made and the original work is properly cited (including links to both the formal publication through the relevant DOI and the license). See: https://creativecommons.org/licenses/by-nc-nd/4.0/.

\section{References}

1. Kim JH, Han E. Endometriosis and Female Pelvic Pain. Semin Reprod Med 2018;36:143-51.

2. Fauconnier A, Chapron C. Endometriosis and pelvic pain: epidemiological evidence of the relationship and implications. Hum Reprod Update 2005;11:595-606.

3. Ferrero S, Barra F, Leone Roberti Maggiore U. Current and Emerging Therapeutics for the Management of Endometriosis. Drugs 2018;78:995-1012.

4. Falcone T, Flyckt R. Clinical Management of Endometriosis. Obstet Gynecol 2018;131:557-71.

5. Anaf V, Simon P, El Nakadi I, et al. Relationship between endometriotic foci and nerves in rectovaginal endometriotic nodules. Hum Reprod 2000;15:1744-50.

6. Berkley KJ, Rapkin AJ, Papka RE. The pains of endometriosis. Science 2005;308:1587-9.

7. Zhang $\mathrm{X}$, Yao $\mathrm{H}$, Huang $\mathrm{X}$, et al. Nerve fibres in ovarian endometriotic lesions in women with ovarian endometriosis. Hum Reprod 2010;25:392-7.

8. McKinnon B, Bersinger NA, Wotzkow C, et al. Endometriosis-associated nerve fibers, peritoneal fluid cytokine concentrations, and pain in endometriotic lesions from different locations. Fertil Steril 2012;97:373-80.

9. Kajitani T, Maruyama T, Asada H, et al. Possible involvement of nerve growth factor in dysmenorrhea and dyspareunia associated with endometriosis. Endocr J 2013;60:1155-64.

10. Ding S, Zhu T, Tian Y, et al. Role of Brain-Derived
Neurotrophic Factor in Endometriosis Pain. Reprod Sci 2018;25:1045-57.

11. Hirota Y, Osuga Y, Koga K, et al. Possible implication of midkine in the development of endometriosis. Hum Reprod 2005;20:1084-9.

12. Wessels JM, Kay VR, Leyland NA, et al. Assessing brainderived neurotrophic factor as a novel clinical marker of endometriosis. Fertil Steril 2016;105:119-28.e285.

13. Rocha AL, Vieira EL, Ferreira MC, et al. Plasma brainderived neurotrophic factor in women with pelvic pain: a potential biomarker for endometriosis? Biomark Med 2017;11:313-7.

14. Berkley KJ, Dmitrieva N, Curtis KS, et al. Innervation of ectopic endometrium in a rat model of endometriosis. Proc Natl Acad Sci U S A 2004;101:11094-8.

15. Mechsner S, Schwarz J, Thode J, et al. Growth-associated protein 43-positive sensory nerve fibers accompanied by immature vessels are located in or near peritoneal endometriotic lesions. Fertil Steril 2007;88:581-7.

16. Wang G, Tokushige N, Russell P, et al. Hyperinnervation in intestinal deep infiltrating endometriosis. J Minim Invasive Gynecol 2009;16:713-9.

17. Lai Wing Sun K, Correia JP, Kennedy TE. Netrins: versatile extracellular cues with diverse functions. Development 2011;138:2153-69.

18. Ishii N, Wadsworth WG, Stern BD, et al. UNC-6, a laminin-related protein, guides cell and pioneer axon migrations in C. elegans. Neuron 1992;9:873-81.

19. Rajasekharan S, Kennedy TE. The netrin protein family. Genome Biol 2009;10:239.

20. Dun XP, Parkinson DB. Role of Netrin-1 Signaling in Nerve Regeneration. Int J Mol Sci 2017;18:491.

21. Tu T, Zhang C, Yan H, et al. CD146 acts as a novel receptor for netrin-1 in promoting angiogenesis and vascular development. Cell Res 2015;25:275-87.

22. Lee HK, Seo IA, Seo E, et al. Netrin-1 induces proliferation of Schwann cells through Unc5b receptor. Biochem Biophys Res Commun 2007;362:1057-62.

23. Grandin M, Meier M, Delcros JG, et al. Structural Decoding of the Netrin-1/UNC5 Interaction and its Therapeutical Implications in Cancers. Cancer Cell 2016;29:173-85.

24. Rosenberger P, Schwab JM, Mirakaj V, et al. Hypoxiainducible factor-dependent induction of netrin-1 dampens inflammation caused by hypoxia. Nat Immunol 2009;10:195-202.

25. Varadarajan SG, Kong JH, Phan KD, et al. Netrin1 Produced by Neural Progenitors, Not Floor Plate Cells, Is 
Required for Axon Guidance in the Spinal Cord. Neuron 2017;94:790-799.e3.

26. Dominici C, Moreno-Bravo JA, Puiggros SR, et al. Floorplate-derived netrin-1 is dispensable for commissural axon guidance. Nature 2017;545:350-4.

27. Madison RD, Zomorodi A, Robinson GA. Netrin-1 and peripheral nerve regeneration in the adult rat. Exp Neurol 2000;161:563-70.

28. Ramkhelawon B, Hennessy EJ, Menager M, et al. Netrin-1 promotes adipose tissue macrophage retention and insulin resistance in obesity. Nat Med 2014;20:377-84.

29. Yim J, Kim G, Lee BW, et al. Relationship Between Circulating Netrin-1 Concentration, Impaired Fasting Glucose, and Newly Diagnosed Type 2 Diabetes. Front Endocrinol (Lausanne) 2018;9:691.

30. Mirakaj V, Thix CA, Laucher S, et al. Netrin-1 dampens pulmonary inflammation during acute lung injury. Am J Respir Crit Care Med 2010;181:815-24.

31. van Gils JM, Derby MC, Fernandes LR, et al. The neuroimmune guidance cue netrin-1 promotes atherosclerosis by inhibiting the emigration of macrophages from plaques. Nat Immunol 2012;13:136-43.

32. Hadi T, Boytard L, Silvestro M, et al. Macrophage-derived netrin-1 promotes abdominal aortic aneurysm formation by activating MMP3 in vascular smooth muscle cells. Nat Commun 2018;9:5022.

33. Itoh F, Komohara Y, Takaishi K, et al. Possible involvement of signal transducer and activator of transcription-3 in cell-cell interactions of peritoneal macrophages and endometrial stromal cells in human endometriosis. Fertil Steril 2013;99:1705-13

34. Bacci M, Capobianco A, Monno A, et al. Macrophages are alternatively activated in patients with endometriosis and required for growth and vascularization of lesions in a mouse model of disease. Am J Pathol 2009;175:547-56.

35. Lousse JC, Van Langendonckt A, Gonzalez-Ramos R, et al. Increased activation of nuclear factor-kappa B (NFkappaB) in isolated peritoneal macrophages of patients with endometriosis. Fertil Steril 2008;90:217-20.

36. Gou Y, Li X, Li P, et al. Estrogen receptor $\beta$ upregulates CCL2 via NF- $\kappa \mathrm{B}$ signaling in endometriotic stromal cells and recruits macrophages to promote the pathogenesis of endometriosis. Hum Reprod 2019;34:646-58.

37. Wu J, Xie H, Yao S, et al. Macrophage and nerve interaction in endometriosis. J Neuroinflammation 2017;14:53.

38. Tofaris GK, Patterson PH, Jessen KR, et al. Denervated Schwann cells attract macrophages by secretion of leukemia inhibitory factor (LIF) and monocyte chemoattractant protein-1 in a process regulated by interleukin-6 and LIF. J Neurosci 2002;22:6696-703.

39. Liang $\mathrm{Y}, \mathrm{Xie} \mathrm{H}, \mathrm{Wu} \mathrm{J}$, et al. Villainous role of estrogen in macrophage-nerve interaction in endometriosis. Reprod Biol Endocrinol 2018;16:122.

40. Cattin AL, Burden JJ, Van Emmenis L, et al. MacrophageInduced Blood Vessels Guide Schwann Cell-Mediated Regeneration of Peripheral Nerves. Cell 2015;162:1127-39.

41. Gordon S, Pluddemann A, Martinez Estrada F. Macrophage heterogeneity in tissues: phenotypic diversity and functions. Immunol Rev 2014;262:36-55.

42. Takebayashi A, Kimura F, Kishi Y, et al. Subpopulations of macrophages within eutopic endometrium of endometriosis patients. Am J Reprod Immunol 2015;73:221-31.

43. Cominelli A, Gaide Chevronnay HP, Lemoine P, et al. Matrix metalloproteinase-27 is expressed in CD163+/ CD206+ M2 macrophages in the cycling human endometrium and in superficial endometriotic lesions. Mol Hum Reprod 2014;20:767-75.

44. Ding S, Zhu L, Tian Y, et al. P2X3 receptor involvement in endometriosis pain via ERK signaling pathway. PLoS One 2017;12:e0184647.

45. Finci LI, Kruger N, Sun X, et al. The crystal structure of netrin-1 in complex with DCC reveals the bifunctionality of netrin-1 as a guidance cue. Neuron 2014;83:839-49.

46. Webber CA, Christie KJ, Cheng C, et al. Schwann cells direct peripheral nerve regeneration through the Netrin-1 receptors, DCC and Unc5H2. Glia 2011;59:1503-17.

47. Ke X, Li Q, Xu L, et al. Netrin-1 overexpression in bone marrow mesenchymal stem cells promotes functional recovery in a rat model of peripheral nerve injury. J Biomed Res 2015;29:380-9.

48. Park JI, Seo IA, Lee HK, et al. Netrin inhibits regenerative axon growth of adult dorsal root ganglion neurons in vitro. J Korean Med Sci 2007;22:641-5.

49. Laskin DL, Sunil VR, Gardner CR, et al. Macrophages and tissue injury: agents of defense or destruction? Annu Rev Pharmacol Toxicol 2011;51:267-88.

50. Chen P, Bonaldo P. Role of macrophage polarization in tumor angiogenesis and vessel normalization: implications for new anticancer therapies. Int Rev Cell Mol Biol 2013;301:1-35.

51. Jensen AL, Collins J, Shipman EP, et al. A subset of human uterine endometrial macrophages is alternatively activated. Am J Reprod Immunol 2012;68:374-86.

52. Wang Y, Fu Y, Xue S, et al. The M2 polarization of macrophage induced by fractalkine in the endometriotic 
milieu enhances invasiveness of endometrial stromal cells. Int J Clin Exp Pathol 2014;7:194-203.

53. Nie MF, Xie Q, Wu YH, et al. Serum and Ectopic Endometrium from Women with Endometriosis Modulate Macrophage M1/M2 Polarization via the Smad2/Smad3 Pathway. J Immunol Res 2018;2018:6285813.

54. Campbell L, Emmerson E, Williams H, et al. Estrogen receptor-alpha promotes alternative macrophage activation during cutaneous repair. J Invest Dermatol 2014;134:2447-57.

55. Wang Y, Chen H, Wang N, et al. Combined 17betaEstradiol with TCDD Promotes M2 Polarization of Macrophages in the Endometriotic Milieu with Aid of the Interaction between Endometrial Stromal Cells and Macrophages. PLoS One 2015;10:e0125559.

56. Yang W, Lu Y, Xu Y, et al. Estrogen represses hepatocellular carcinoma (HCC) growth via inhibiting alternative activation of tumor-associated macrophages (TAMs). J Biol Chem 2012;287:40140-9.

57. Martinez FO, Gordon S. The M1 and M2 paradigm of macrophage activation: time for reassessment. F1000Prime Rep 2014;6:13.

58. Murray PJ. Macrophage Polarization. Annu Rev Physiol 2017;79:541-66.

59. Ginhoux F, Schultze JL, Murray PJ, et al. New insights into the multidimensional concept of macrophage ontogeny, activation and function. Nat Immunol 2016;17:34-40.

60. Goldmann O, von Kockritz-Blickwede M, Holtje C, et al. Transcriptome analysis of murine macrophages in response to infection with Streptococcus pyogenes reveals an unusual activation program. Infect Immun 2007;75:4148-57.

61. Chan G, Bivins-Smith ER, Smith MS, et al. Transcriptome analysis reveals human cytomegalovirus reprograms monocyte differentiation toward an M1 macrophage. J Immunol 2008;181:698-711.

62. Paradisi A, Maisse C, Bernet A, et al. NF-kappaB regulates netrin-1 expression and affects the conditional tumor suppressive activity of the netrin-1 receptors. Gastroenterology 2008;135:1248-57.

63. Lv J, Sun X, Ma J, et al. Netrin-1 induces the migration of Schwann cells via p38 MAPK and PI3K-Akt signaling pathway mediated by the UNC5B receptor. Biochem Biophys Res Commun 2015;464:263-8.

64. Castets M, Mehlen P. Netrin-1 role in angiogenesis: to be or not to be a pro-angiogenic factor? Cell Cycle 2010;9:1466-71.

65. Ly NP, Komatsuzaki K, Fraser IP, et al. Netrin-1 inhibits leukocyte migration in vitro and in vivo. Proc Natl Acad
Sci U S A 2005;102:14729-34.

66. Mao X, Xing H, Mao A, et al. Netrin-1 attenuates cardiac ischemia reperfusion injury and generates alternatively activated macrophages. Inflammation 2014;37:573-80.

67. Chen H, Chen Q, Luo Q. Expression of netrin-1 by hypoxia contributes to the invasion and migration of prostate carcinoma cells by regulating YAP activity. Exp Cell Res 2016;349:302-9.

68. Han P, Fu Y, Liu J, et al. Netrin-1 promotes cell migration and invasion by down-regulation of BVES expression in human hepatocellular carcinoma. Am J Cancer Res 2015;5:1396-409.

69. Yin K, Wang L, Zhang X, et al. Netrin-1 promotes gastric cancer cell proliferation and invasion via the receptor neogenin through $\mathrm{PI} 3 \mathrm{~K} / \mathrm{AKT}$ signaling pathway. Oncotarget 2017;8:51177-89.

70. Fitamant J, Guenebeaud C, Coissieux MM, et al. Netrin-1 expression confers a selective advantage for tumor cell survival in metastatic breast cancer. Proc Natl Acad Sci U S A 2008;105:4850-5.

71. Zhang J, Wang H, Meng Q, et al. Expression of MTA1 in endometriosis and its relationship to the recurrence. Medicine (Baltimore) 2018;97:e12115.

72. Bedir R, Sehitoglu I, Balik G, et al. The role of the adhesion molecule Nectin-4 in the pathogenesis of endometriosis. Clin Exp Obstet Gynecol 2016;43:463-6.

73. Timologou A, Zafrakas M, Grimbizis G, et al. Immunohistochemical expression pattern of metastasis suppressors KAI1 and KISS1 in endometriosis and normal endometrium. Eur J Obstet Gynecol Reprod Biol 2016;199:110-5.

74. Rosa-e-Silva JC, Garcia SB, de Sa Rosa-e-Silva AC, et al. Increased cell proliferation in experimentally induced endometriosis in rabbits. Fertil Steril 2010;93:1637-42.

75. Passacquale G, Phinikaridou A, Warboys C, et al. Aspirin-induced histone acetylation in endothelial cells enhances synthesis of the secreted isoform of netrin-1 thus inhibiting monocyte vascular infiltration. Br J Pharmacol 2015;172:3548-64.

76. Guo X, Ding S, Li T, et al. Macrophage-derived netrin-1 is critical for neuroangiogenesis in endometriosis. Int J Biol Macromol 2020;148:226-37.

Cite this article as: Ding S, Guo X, Zhu L, Wang J, Li T, Yu Q, Zhang X. Macrophage-derived netrin-1 contributes to endometriosis-associated pain. Ann Transl Med 2021;9(1):29. doi: $10.21037 / \mathrm{atm}-20-2161$ 